of patients receiving monotherapy or combination therapy at treatment initiation.

Results: 1950 patients were included in the matched population (1300 bDMARD initiators; 650 tofacitinib initiators). Patients were predominantly aged 55 to 74 years $(57.8 \%)$, and female $(81.2 \%)$. At baseline, median disease duration was 107 and 120 months, with $16.1 \%$ and $17.3 \%$ of patients in DAS28-ESR defined disease remission for the bDMARD and tofacitinib groups respectively. After three months of treatment, $49.1 \%$ and $49.7 \%$ had achieved DAS remission and after 18 months of treatment, $52.4 \%$ and $57.8 \%$ of patients had achieved DAS remission in the bDMARD and tofacitinib groups respectively. At 18 months the percentage of patients achieving CDAI/SDAI remission was similar with $29.2 \%$ / $29.0 \%$ bDMARD patients and $30.9 \% / 30.5 \%$ tofacitinib patients reporting CDAI/SDAI remission respectively. The median persistence of treatment was similar for bDMARD and tofacitinib groups: $33.8(95 \% \mathrm{Cl} 28.8$ to $40.4)$ and $34.2(95 \% \mathrm{Cl} 32.2$ to not reached) months respectively. In the overall population, more patients were prescribed tofacitinib as monotherapy (43.4\%) compared to bDMARD monotherapy (33.4\%).

Conclusion: In this analysis of a large real world dataset, tofacitinib demonstrated treatment effectiveness and persistence that was similar to bDMARDs. Overall, there was a trend for more use of tofacitinib as monotherapy than bDMARDs.

Acknowledgement: We wish to acknowledge the Australian rheumatologists who contribute data to OPAL for research.

Disclosure of Interests: Paul Bird Consultant for: Advisory boards for Eli Lily, Pfizer, Roche, AbbVie, Geoff Littlejohn Consultant for: Sat on Advisory Boards for AbbVie, Janssen, Roche, Pfizer, BMS, and Sanofi Genzyme, Belinda Butcher Consultant for: Consultant biostatistician and medical writer providing services to AbbVie, BMS, Janssen, MSD, Pfizer, UCB., Employee of: Janssen, Tegan Smith Grant/research support from: AbbVie, Consultant for: Provided medical writing services to Genentech, BioMarin, MSD, AbbVie, Roche, Actelion, Gilead, Kazia, Menarini, Candida da Fonseca Pereira Employee of: Pfizer, David Witcombe Shareholder of: Pfizer, Employee of: Pfizer, Hedley Griffiths Grant/research support from: Research funded by AbbVie, Janssen, BMS, Consultant for: Advisory boards for Sanofi, Pfizer, Novartis, Janssen DOI: 10.1136/annrheumdis-2019-eular.5216

\section{FRI0141 EFFICACY OF JAK-INHIBITORS VERSUS BIOLOGIC DMARDS ON QUALITY OF LIFE IN RHEUMATOID ARTHRITIS :A META ANALYSIS OF RANDOMIZED CONTROLLED TRIALS}

Mamadaly Boudhabhay ${ }^{1}$, Thomas Barnetche ${ }^{2}$, Pascale Vergne-Salle ${ }^{1}{ }^{1} \mathrm{CHU}$ de Limoges, Limoges, France; ${ }^{2} \mathrm{CHU}$ de Bordeaux, Bordeaux, France

Background: Recent studies comparing JAK-inhibitors (Jak-i) and adalimumab seem to show a better efficacy of JAK-i on patient-reported outcomes in rheumatoid arthritis (RA.)

Objectives: As there is no study comparing directly the JAK-i with other biologic DMARDs (bDMARDs), we performed a meta-analysis and compared the effect size of JAK-iand bDMARD versus synthetic DMARDs (sDMARDs) on quality of life.

Methods: We performed a systematic review of the literature until May 2018 using database including : MEDLINE (via PUBMED), EMBASE and abstracts from the ACR and EULAR congresses 2015-2017. We selected all randomized controlled trials (RCT) comparing quality of life (evaluated by SF36) in patient with rheumatoid arthritis treated with bDMARD or JAK-i versussDMARDs. We performed meta-analysis comparing the effect size of JAK-i (versus sDMARDs) and bDMARD (versus sDMARDs) on PCS SF36 and MCS SF36 at 12 weeks.

Statistical analysis determined in each study effect size.

Pooled ES were computed by meta-analysis. Data were analyzed using the inverse variance approach

Results: The literature search identified 240 articles plus one found by manuel search and no congress abstract. Finally, 44 articles met the inclusion criteria.

JAK- $i$ and bDMARD showed higherlevel of quality of life than conventional therapies:

- For the SF36 PCS at 12 weeks:JAK-i:+4,82 IC95\% [3,88, 5.77] and bDMARDs : +3,99 IC95\% $[2,81,5,18]$

- For the SF36 MCS a 12 weeks: JAK-i: +3,42 IC95\% [2.24, 4,60] and bDMARD: 2,99 IC95\% [2.02, 3.96]

The range of the confidence intervals seems similar between JAK-I and bDMARDs.

SF36 PCS at 12 weeks:
Results for JAK-i:

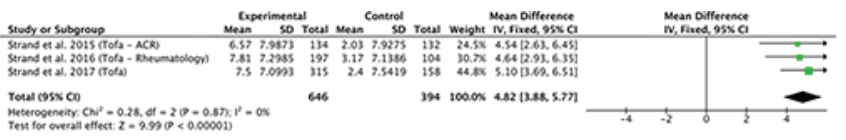

Results. for bDMARDs:

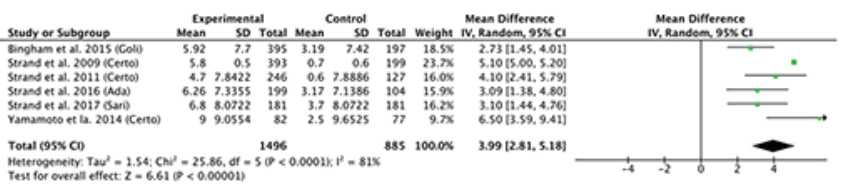

SF36 MCS at 12 weeks:

-Results for JAK-i:

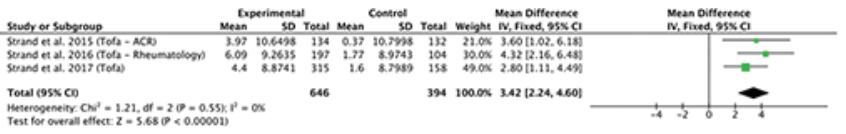

-Results for bDMARDs:

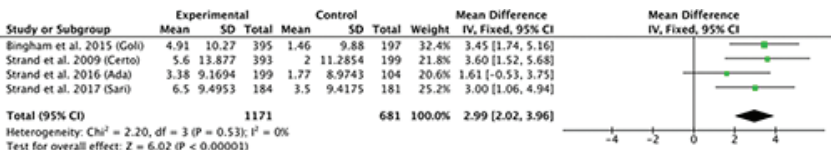

Conclusion: In this meta-analysis, JAK-i and bDMARD showed bette SF36 PCS and MCS at 12 weeks in comparison with sDMARDs. Although there is no significant difference, there seems to be a trend toward a bet ter efficacy of JAK-I compared to bDMARD on quality of life.

The range of the confidence intervals seems similar between JAK-I and bDMARDs, suggesting a similar efficiency on the components of the SF36. More head-to-head studies are needed to draw definitive conclusions on potential efficacy differences between JAK-inhibitor and bDMARDs in RA. Disclosure of Interests: Mamadaly Boudhabhay: None declared, Thomas Barnetche Consultant for: Roche SAS, Pascale Vergne-Salle: None declared

DOI: 10.1136/annrheumdis-2019-eular.7102

\section{FRI0142 SAFETY OF THE METHOTREXATE-LEFLUNOMIDE COMBINATION IN THE BRAZILIAN REGISTRY OF BIOLOGICAL THERAPIES IN RHEUMATIC DISEASES (BIOBADABRASIL)}

Markus Bredemeier, M Pinheiro, C Macieira, A Duarte, B Stadler, R Ranza, Ana Medeiros, V Valim, M Bertolo, J Miranda, C Brenol, G Castro, V Fernandes, D Titton, F Sauma, I Pereira, R Botelho, H Carvalho, A Hayata, P Louzada,

A Ranzolin, I Silveira, S Schowalski, D Feldman, I Laurindo, J Provenza, Brazilian Society of Rheumatology. BiobadaBrasil, São Paulo, Brazil

Background: The combination of methotrexate (MTX) with leflunomide (LEF), despite being effective in the therapy of rheumatoid arthritis (RA) [1], has not been widely accepted[2,3]. In spite of evidence that the MTX-LEF combination is generally safe $[1,4,5]$, the relatively small numbe of patients and treatment courses have not permitted firm conclusions.

Objectives: To evaluate the safety of the combination MTX-LEF in Brazilian patients with RA included in BiobadaBrasil.

Methods: BiobadaBrasil is a multicentric prospective cohort study involving patients with rheumatic diseases who started the first biologic or a synthetic disease modifying anti-rheumatic drug (DMARD)[6]. This analysis includes RA (2010 criteria) patients recruited from Jan 2009 to Aug 2018 ,followed-up for one or multiple courses of treatment until censoring (latest date, September 03,2018) or occurrence of the outcome of interest. The primary outcome was the incidence of any serious AE (SAE) Secondary outcomes were infectious, non-mycobacterial pulmonary infectious, hepatic, hematologic and cardiovascular SAE. Multivariate Cox pro portional hazards models (with DMARDs included as time-varying covariates) were used to estimate hazard ratios (HR) and 95\% confidence intervals $(\mathrm{Cl})$; analyses were performed with the Survival package of $\mathrm{R}$. 
Results: Sample: 2055 RA patients, female $=85.1 \%$, median disease duration=6.02 yrs; mean (SD) age $=50.3$ (12.1) yrs; mean (SD) DAS28 $=5.3$ (3.1); seronegative $\mathrm{RA}=14.1 \%$; median follow-up duration=3.9 yrs. In total, 565 patients received 664 courses of the MTX-LEF combination (median duration, 2.5 years/course; 2209 person-years). The incidence of SAE was $4.75 / 100$ patient-years in the entire sample. There was no significant increase in the risk of any of the outcomes with the use of combined therapy (table 1) comparing with methotrexate (without leflunomide). The use of antimalarials was associated with reduced risk of SAE (adjusted $\mathrm{HR}=0.62,95 \% \mathrm{Cl} 0.48$ to $0.79, \mathrm{P}<0.001$ ), while sulfasalazine (adj. $\mathrm{HR}=$ 1.78, 1.18 to 2.68, $\mathrm{P}=0.006$ ) and biologic DMARDs/tofacitinib (adj. $\mathrm{HR}=$ $1.67,1.31$ to $2.12, P<0.001$ ) increased the risk of $S A E$.

Table 1

\begin{tabular}{lcc}
\hline Outcome(number of SAE) & $\mathrm{HR}(95 \% \mathrm{Cl}), \mathrm{p}$ Value & $\mathrm{HR}(95 \% \mathrm{Cl}), \mathrm{p}$ Value \\
\hline SAE (457) & $1.00(0.78-1.26)$, & $1.06(0.83-1.35)$, \\
& $\mathrm{p}=0.970$ & $\mathrm{p}=0.629$ \\
SAE infections (228) & $1.1(0.79-1.55), \mathrm{p}=0.538$ & $1.24(0.89-1.75)$, \\
& $\mathrm{p}=0.207$ \\
SAE non-mycobacterial lung infections & $0.90(0.50-1.62)$, & $0.97(0.53-1.74)$, \\
(78) & $\mathrm{p}=0.733$ & $\mathrm{p}=0.908$ \\
SAE hepatic AE(14) & $1.12(0.28-4.48)$, & $\mathrm{NA}$ \\
SAE hematologic (10) & $\mathrm{p}=0.873$ & $\mathrm{NA}$ \\
& $2.09(0.52-8.36)$, & \\
SAE CV (61) & $\mathrm{p}=0.299$ & $1.11(0.58-2.12)$, \\
& $1.22(0.65-2.30)$, & $\mathrm{p}=0.755$ \\
\hline
\end{tabular}

${ }^{*}$ Comparing with MTX (without leflunomide) and adjusted for the use of LEF (without MTX) and a category representing absence of MTX and LEF. †Adjusted also for time-fixed covariates (age, gender, smoking, history of malignancy, diabetes, hypertension, renal failure, ischemic cardiomyopathy, bronchopulmonary obstructive disease) and time-varying covariates (use of sulfasalazine, antimalarials, biologic DMARDs/tofacitinib, and corticosteroids). SAE: serious adverse events, MTX: methotrexate, LEF: leflunomide, NA: not applicabledue to reduced number of events, CV: cardiovascular.

Conclusion: BIOBADABRASIL results suggest that the combination of methotrexate and leflunomide is safe in thetreatment of RA.

\section{REFERENCES:}

[1] Ann Intern Med 2002; 137: 726

[2] Ann Rheum Dis 2010; 69: 43

[3] Ann Pharma cother 2004; 38: 1206

[4] J Rheumatol 2013; 40: 228.

[5] Rev Bras Reumatol 2011; 51: 141/51:152.

\section{Acknowledgement: monitor P Cabral}

Disclosure of Interests: Markus Bredemeier: None declared, M Pinheiro Consultant for: Janssen, Pfizer, Speakers bureau: Abbot,Janssen,Novartis, C Macieira: None declared, A Duarte: None declared, B Stadler: None declared, R Ranza: None declared, Ana Medeiros: None declared, V Valim: None declared, M Bertolo: None declared, J Miranda Speakers bureau: Pfizer, C Brenol Speakers bureau: Pfizer, Roche, Janssen, Bristol., G Castro: None declared, V Fernandes Speakers bureau: Janssen, D Titton: None declared, F Sauma: None declared, I Pereira: None declared, R Botelho: None declared, H Carvalho: None declared, A Hayata: None declared, P Louzada: None declared, A Ranzolin: None declared, I Silveira: None declared, S Schowalski: None declared, D Feldman: None declared, I Laurindo Consultant for: Abbvie, UCB, GSK, JANSSEN, LILLY, NOVARTIS, PFIZER, Paid instructor for: Abbvie, JANSSEN, Speakers bureau: Abbvie, UCB, GSK, JANSSEN, LILLY, NOVARTIS, PFIZER, ROCHE, J Provenza: None declared DOI: 10.1136/annrheumdis-2019-eular.3867

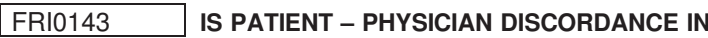 ASSESSMENTS OF BURDEN OF RHEUMATOID ARTHRITIS A DETERMINANT OF METHOTREXATE ADHERENCE?}

Ana Bulatovic ${ }^{1}$, Natasa Miketic ${ }^{1}$, Milan Bogojevic ${ }^{1}$, Svetlana Aligrudic $^{2}$, Rifat Medjedovic ${ }^{1}$, Darija Kisic Tepavcevic ${ }^{3} .{ }^{1}$ Clinical center of Montenegro, Podgorica, Montenegro; ${ }^{2}$ Mercur Nera Polyclinic, Podgorica, Montenegro; ${ }^{3}$ Institute of public health, Belgrade, Serbia

Background: Accurate assessments of disease activity in rheumatoid arthritis (RA) have a crucial role in establishing disease severity and monitoring response to treatment. There is no objective, numerical measures to estimate RA severity and treatment response. A frequently used means of quantifying the overall perception of disease activity is through an subjective assessment of global disease activity on a visual analogue scale (VAS), both by the patient, and by the physician, as well. The common direction of the discrepancy usually points toward bet ter rating by the physicians than by the patients themselves, leading to potential medication adherence.

Objectives: The aims of the study were to explore the presence of disagreement between patients' and physicians' assessment of global dis ease severity, as well as to investigate the possible correlation between patient - physician discordance in assessments of RA burden and methotrexate adherence.

Methods: In the period between May 1 and September 15, 2019, 98 consecutive RA patients who were treated in Clinical center of Montenegro and private clinic "Merkur Nera" randomly chosen Montenegrin clinics were enrolled in this multi-centric cross-sectional study. The inclusion criteria were as follows: age $\geq 18$ years, diagnosis of RA of at least 6 months, current methotrexate (MTX) use for at least 1 month (with or without concomitant usage of another RA drugs), and written informed consent. Non-adherence to MTX was defined as $>1$ dose missed against medical advice. The global disease activity is estimated by VAS (using a 0-10 ordinal scale), both by the patient, and by the physician. The differences between groups are assessed using the Mann-Whitney U-test. The correlation between the patient - physician discordance and MTX adherence is evaluated using the Spearman rank correlation.

Results: The most of the participants (87.8\%) were female with median current age of 57.5 years (range $21-83$ years). The median duration of RA was 8 years (range 0-34 years), while the median duration of MTX treatment was 6 years (range 0-26 years). The median value of VAS score estimated both, by the patients and their physician was 5 , with no statistically significant difference between these two groups $(Z=1.447$; $p$ $=0.748$ ). The analysis of patient - physician discordance in VAS assessment showed that full agreement is achieved in $76(77.6 \%)$ cases, while in $21(21,4 \%)$ RA patients their doctors underestimated their self-perception of disease burden. In only one participant, the physician overestimated patient's perception of RA severity. In total sample the selfestimated prevalence of MTX non-adherence was $32.7 \%$. However, the analyses of the frequency of MTX non-adherence in sub-cohorts stratified by the presence of patient - physician discordance in VAS assessment showed that in "concordance group" the prevalence was 26.3\% (20 out of 76 RA patients), while in "disconcordance group" the prevalence was $54.5 \%$ (12 out of 22 RA patients), with statistically significant difference between these two groups $(Z=-5.745 ; p<0.001)$. Statistically significant correlation has been observed between presence of patient - physician discordance in VAS assessment and MTX non-adherence $(\rho=0,427 ;$ p $<0.001)$.

Conclusion: The results of our study have shown that the presence of patient - physician discordance in assessment of global RA activity could deeply influence the MTX adherence in a Montenegrion sample of patients with RA. This finding emphasizes the need to focus on patients preferences and values to deliver individualized patient-centered care that could potentially enhance adherence and consequently achieved optimally control of disease activity.

Disclosure of Interests: None declared

DOI: 10.1136/annrheumdis-2019-eular.8002

\section{FRI0144 JOINT-SPECIFIC RESPONSES TO TOFACITINIB AND ADALIMUMAB IN RHEUMATOID ARTHRITIS: A POST HOC ANALYSIS OF DATA FROM ORAL STANDARD AND ORAL STRATEGY}

Adrian Ciurea ${ }^{1}$, Oliver Distler ${ }^{1}$, Tim Killeen ${ }^{2}$, Ermeg Akylbekova ${ }^{3}$, Kenneth Kwok ${ }^{4}$, Lisy Wang ${ }^{5}$, Caroline Ospelt ${ }^{1}$, Mojca Frank-Bertoncelj ${ }^{1}$. ${ }^{1}$ University Hospital Zürich, Zürich, Switzerland; ${ }^{2}$ Pfizer AG, Zürich, Switzerland; ${ }^{3}$ IQVIA, Durham, NC, United States of America; ${ }^{4}$ Pfizer Inc, New York, NY, United States of America; ${ }^{5}$ Pfizer Inc, Groton, CT, United States of America

Background: Inflammatory arthritides affect joints variably despite systemic inflammatory cues. Anatomical site-specific differences have been seen in the transcriptome and function of synovial fibroblasts from different joints, including evidence that some joints in rheumatoid arthritis (RA) show dif ferential methylation of genes encoding biological pathways, such as interleukin 6 signalling via the JAK-STAT pathway. ${ }^{2}$ Whether such site-specific JAK-STAT sensitivity translates into joint-specific responses to therapeutic JAK inhibition is unknown. Tofacitinib is an oral JAK inhibitor for the treatment of RA.

Objectives: To explore joint-specific responses to tofacitinib and adalimumab (ADA) in RA clinical trials. 